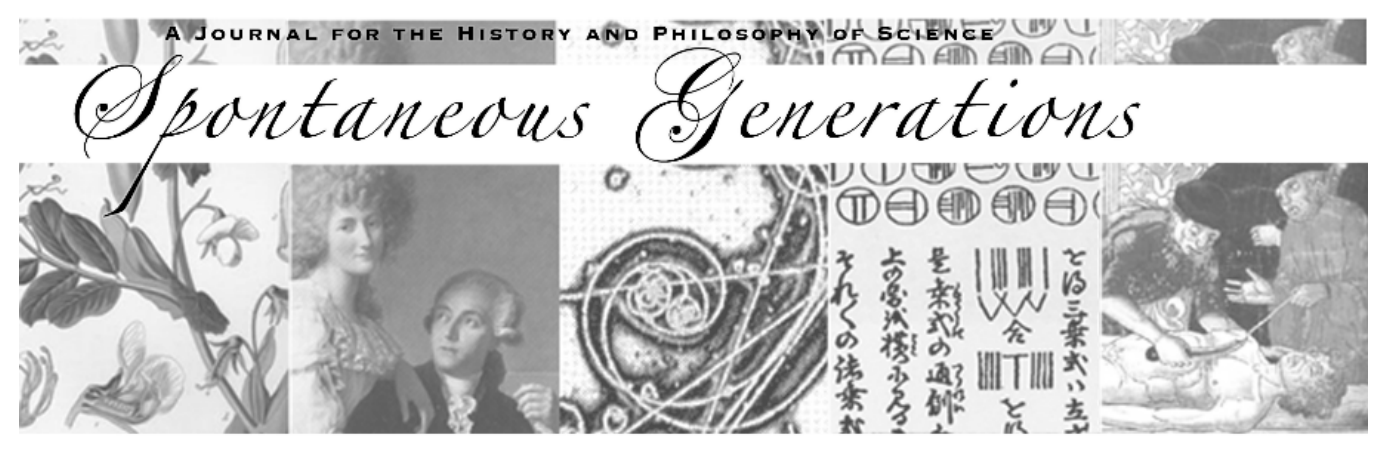

\title{
Trouble with Images in Computational Physics
}

\section{Author(s): Matt Spencer}

Source: Spontaneous Generations: A Journal for the History and Philosophy of Science, Vol. 6, No. 1 (2012) 34-42.

Published by: The University of Toronto

DOI: 10.4245 /sponge.v6i1.16119

\section{EDITORIAL OFFICES}

Institute for the History and Philosophy of Science and Technology

Room 316 Victoria College, 91 Charles Street West

Toronto, Ontario, Canada M5S 1K7

hapsat.society@utoronto.ca

Published online at jps.library.utoronto.ca/index.php/SpontaneousGenerations ISSN 19130465

Founded in 2006, Spontaneous Generations is an online academic journal published by graduate students at the Institute for the History and Philosophy of Science and Technology, University of Toronto. There is no subscription or membership fee. Spontaneous Generations provides immediate open access to its content on the principle that making research freely available to the public supports a greater global exchange of knowledge. 
FocusEd Discussion

Peer-Reviewed

\title{
Trouble with Images in Computational Physics ${ }^{*} \dagger$
}

\author{
Matt Spencer
}

\begin{abstract}
Over 18 months of ethnographic fieldwork with a group of computational physicists, I encountered many negative assessments of the part that images should play in the accomplishment of good research. In this essay I explore the question of where these anxieties might come from and what they mean. Using Bachelard's philosophy, I first point to the role that the image plays in conditioning the imagination and in training intuitive judgement. But to get to the bottom of the trouble with images we are led through Rheinberger and Stiegler to a view of scientific cognition that extends beyond the mind to prosthetic circuits of artefacts, including both images and written inscriptions. Rather than locating the problem as one of the relation between the image and what it represents, I argue for the importance of general cultural difficulties in managing and manipulating artefactual assemblages.
\end{abstract}

"Images lie," says one scientist. "It is much better to work with numbers." A colleague of hers commented that "there is a substantial percentage of scientists, maybe even 10 percent, who will see a pretty picture and just want to use it, without even knowing how it is validated. I think that is just disturbing." More strong language from a third source: "I think pretty pictures are an utter waste of time" and a fourth: "Images tell you nothing."

This trope-"representation gone bad"-is hardly something new. It has long been part of our Western heritage (Latour and Weibel 2002). From Plato's expulsion of the artists from the Republic to the history of smashed idols, representations embody an entrenched antagonism between the authentic and

* Thanks to the anonymous reviewers, editor and copyeditor, all of whom helped greatly in preparing the transcript for publication. This research was funded by the UK Arts and Humanities Research Council.

† Received 15 February 2012. Accepted 20 June 2012.

$\ddagger$ Matt Spencer is a PhD student and Visiting Tutor at Goldsmiths Centre for Cultural Studies in London, UK. His research concerns scientific software development, the epistemology of computer simulation, and social scientific and philosophical theories of rationality and representation. Since the summer of 2010, he has been undertaking ethnographic research with the Applied Modelling and Computation Group at Imperial College in London.

1 All quotes are taken from transcripts of interviews with the members of the Imperial College Applied Modeling and Computational Group conducted by the author between 2010 and 2012.

Spontaneous Generations 6:1 (2012) ISSN 1913-0465. University of Toronto.

Copyright 2012 by the HAPSAT Society. Some rights reserved. 
the derivative. In charting the recent history of simulation methods across the sciences, Sherry Turkle (2009, 5, 31, 76-81) shows that computer-generated images emerge as a key locus for anxieties about the legitimacy of these new ways of conducting research. I want to use this focussed discussion to briefly explore the background of these kinds of concerns, which were often voiced in the 32 interviews that I conducted with computational scientists at all stages of their careers. These interviews were one element of an 18 month ethnographic study of a London-based computational physics research group (the Imperial College Applied Modelling and Computation Group).

The anxieties evident in the fragments quoted above stand at odds with the plethora of images created in the course of these scientists' own everyday research. If images are so troublesome, why keep on creating them? My informants work in the fields of geophysical and computational fluid dynamics, using simulations to study engineering, oceanographic, atmospheric, and geological problems. Despite negative assessments, it is undeniable that images play a key role in conducting this research. Most importantly, they provide ways of working with data, a rough and ready "shortcut" to understanding data generated by simulations for which diagnostics have yet to be developed. In each case, it takes time to figure out whether the simulation is doing what you think it is doing, whether what it is doing is the right thing to be doing, and whether it is doing it for the right reasons. It can take a while to develop statistical measures tailored to the specific problem and to implement methods to condense the output data into a variable or set of variables appropriate for validation. In the meantime, many simulations are producing datasets too big to be directly "read." So despite reservations about the eventual value of images, visualisation remains an indispensable technique within the intermediate stages of the investigative process, particularly when the model is in the process of being created. ${ }^{2}$

Images circulate in the laboratory as tools aiding the ongoing flow of research. They are equally objects of fascination and delight. Fluid dynamics research produces some wonderful images of swirling vortices, something that many of my informants are openly proud of. Occasional emails circulate through the group's communication channels calling for the collection of members' latest and best images for use on the website or on posters showing off the group's work. Such images abound in the fluid dynamics literature, adorning websites and textbooks and play no small role in defining the public perceptions of what fluid dynamics is.

We gain a handle on the contrast between the positive and the negative assessments of images quoted at the beginning of this paper if we note that

2 See, for example, M. Monteiro, Reconfiguring evidence: Interacting with digital objects in scientific practice, Computer Supported Cooperative Work 9(3-4) (2010): 335-354; and M. Spencer, Image and practice: Visualisation in computational fluid dynamics research, Interdisciplinary Science Reviews 37(1) (2012): 86-100. 
the latter valuations are all strongly associated with epistemic concerns about persuasion and the legitimacy of arguments. Such concerns rarely referred to codified rules, having more to do with the virtues of conducting oneself appropriately in debate and in writing, the activities which involve presenting research results to a wider (academic, industrial-professional and, occasionally, lay public) audience.

It is necessary to stress that in their criticisms of images, my informants had in mind visualisations of complex domains. They never wanted to extend their criticisms to graphs due to the relatively unambiguous conventional procedures to convert a graph into a table of numbers. In contrast, the visualisations that produce the "pretty pictures" of which they speak only provide a qualitative understanding, and it is much harder to control exactly how such qualitative understandings can support an argument.

It was not, however, because images fail to provide epistemic support that they are regarded as problematic. Many other aspects of any research publication will similarly lack epistemic merit (the snappy title, the font it is printed in, the acknowledgements). It is not because images fail to convince a reader, but because, through a potential akin to pure rhetoric, they can end up being convincing in the wrong way. A beautiful image can be compelling in and of itself, quite aside from whether the simulation that produced it was set up right and quite aside from what specific claims are being argued. My informants were wary not because images fail to convince a reader. Indeed, they generally felt that an image should fail to convince a reader. The wariness arises from the possibility that the images they used might convince their reader of the entirely wrong things for entirely the wrong reasons. The third source, quoted above, went on to contrast the persuasive power of images with that of statistical validation of the model. It is the latter, he felt, that should be the proper locus for persuasion. Several others echoed this sentiment with a much more general contrast between the relative merits of images and "hard numbers."

So how can we account for the coincidence of utility and danger in the image?

For the French epistemologist Gaston Bachelard, scientists must always be wary of images. If science is to progress, it is necessary that scientists disrupt their imaginative faculties, that they find ways to kick the feet out from under intuitive ways of thinking that have been cultivated across the many arenas of daily life. It is essential for modern science, in Bachelard's view, to overcome what he calls "epistemological obstacles" (Bachelard 2002, 24). Past experience has provided us with images through which we make sense of the world, some of which yield false certainties so entrenched that only great efforts will see them shifted. Thus Bachelard would assert that "[a] science that accepts images is, more than any other, a victim of metaphor" (Bachelard 2002, 47).

Substance is one of Bachelard's examples. He writes of the manner in which 
images of interiority and inwardness exerted an influence on the ways in which scientific phenomena have been analysed. These imaged forms of thought are more than ways of speaking: "there is in fact more here than just description by a word: there is explanation by a thought. You think as you see and you think what you see: a speck of dust sticks to an electrified surface and therefore electricity is a glue, a very sticky glue" (Bachelard 2002, 109). Inspired by the challenges posed by relativity and quantum theory to the necessity that Kant supposed governed intuition, Bachelard's "non-Kantian" theory of science is based on its continual overturning of entrenched certainties (Bachelard 1968). Science, therefore, works with, upon, but most importantly, against, the image.

The imagination in Bachelard's view wanders among tropes laid down over a lifetime, especially during childhood, expressed particularly vividly in poetry and in dreams. These intuitions are in constant interaction with new experiences. Patterns in fluid dynamics images (see Figure 1) recall the ways in which we dwell among fluids, in which we bathe and consume them, the ways we paddle, pour, stir, soak, and splash. Certain kinds of images are favoured, as are certain scales, which are conditioned by the bodies and environments we inhabit. As Myers (2006) has shown, far from being disembodied, computational science is profoundly affected by "body-work," and scientists engage with phenomena through a whole range of bodily and gestural entanglements. With Bachelard we can add to this a tension, an ambivalence of such affective processes; while images open certain paths of investigation they may equally constitute a blockage of others.

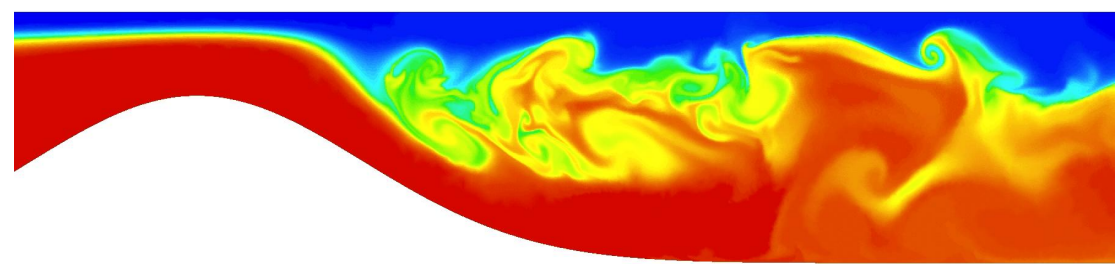

Figure 1. Imperial College Applied Modelling and Computation Group. Visualisation of data generated by a simulation of the generation of internal waves, and their breaking, in stratified flow over a bump

My informants regarded their intuitions as a key resource for judging the success of their manipulations of computer code. Notoriously fragile, the meaning and effect of software may be radically altered with a single character out of place. Some errors in setting up a simulation will effectively simulate the wrong fluid. Many more will totally disturb any supposed connection with fluids whatsoever.

If the image evokes intuitions of fluids, often in this context a moving image, it serves as a rough, provisional indication that the project remains on the right lines. This informal kind of check is thus ubiquitous in the laboratory routine. 
One scientist put it like this:

Would you expect that if you bent a piece of wood into a certain position, and then bent it further, it snaps? If it keeps bending and bending and didn't snap you would say that is unphysical. I guess you could say the same of fluid dynamics. There are just some things that the system just isn't supposed to do.

On several fronts, fluids exceed codified knowledge of what they do. Turbulence, one of the central phenomena of fluid dynamics, implies for modellers that there are dynamics going on at scales smaller than those which they explicitly model. One scientist interview put it enigmatically: "I think one of the best ways to put it is that turbulence is that thing that you can't ever model." There are always phenomena that escape the model, and thus no absolute or "mechanical" means for recognising a fluid to serve as a yardstick against the fallibility of intuition.

Being produced as part of the accomplishment of research while feeding back into its ongoing concerns, images are among the many inscriptions that form the material culture in which research is carried out. But I here want to side with Rheinberger $(1997,106)$ in making the claim that their importance is to be judged "not by what they depict, but by how they work. Immutable mobiles [a term from Latour] fix transient events (make them durable), and in doing so, allow them to be moved in space and time (make them available in many places). That is their power." Rather than keeping with Bachelard in analysing the perception of a singular image, Rheinberger points us towards the many images of the laboratory, and how they connect with the many other inscriptions (text, data, code) found across its domain.

Digital images in computational science emerge out of work with visualisation software, explorations of the vast possibilities for scientists seeing what they have done when making and running simulations. This work, choosing colours, variables to display, contrasts to highlight, viewing angles, is just the start. Any thus created image can be manipulated and explored, and while easily discarded, it can also be rendered mobile, exported, saved, now embodied in a standard format data-file. It can travel and multiply, across many screens, projectors and print media. It can facilitate decisions elsewhere, catalyse discussions, act as a heuristic, and be embedded in new sites of narrative, contrast, and series.

To talk of representation is to talk of a shifting assembly of related traces: "material signs, entities of signification" (Rheinberger 1997, 111; cf. Derrida 1974). The image in Figure 1 is one such trace. It represents internal waves in stratified flow and emerges from a project investigating the physical processes at work in "real world" sea loch systems. But it also represents the data-set that is embodied in its contours and colours (blue standing for fresh water, red for salty, and yellow and green for in-between). Quite aside from any empirical 
target, the image is a way to display this data set, an attempt to render visible what is embodied there. Furthermore, any such generated traces are indexical of the software that produced them and the "model" it embodies. Not confined to a singular motive of studying a sea loch, the research project is also equally concerned with validating the larger software framework, demonstrating that to some degree it should be judged capable of simulating turbulence in stratified flows, a key stepping stone towards simulating many other fluid phenomena. The code itself is further connected with other bodies of software and theory. Rheinberger's approach stresses the dynamics of interaction and substitution among a flat array of relations, and he is therefore "not concerned... with the relation between theory and reality, between concept and object as such" (Rheinberger 1997, 104). Instead, he is "concerned with describing the process of making science as a process in which traces are generated, displaced, and superposed" (Rheinberger 1997, 105). This point of view stands in stark contrast to the general tendency in the philosophy of representation to isolate a single relation and ask of it alone what it does and how it does it.

What Rheinberger describes is a wide field of play, of many images, and many other traces, connected in many ways and involved in a dynamic process of articulation. Looking beyond the images of the imagination described by Bachelard, we also need to appreciate them as cognitively significant things in the world. As Heidegger argued, it may be more appropriate to regard cognition as a worldly practice, rather than as something locked away within the enclosure of a subject: "the perceiving of what is known is not a process of returning with one's booty to the 'cabinet' of consciousness after one has gone out and grasped it; even in perceiving, retaining, and preserving, the Dasein which knows remains outside, and it does so as Dasein" (Heidegger 1978, 89). Beyond their capacity to provoke intuitive responses from a viewer, images can also be seen as artefactual strata that embody in themselves something of the cognitive circuits that comprise the scientists' systems of exploration. They are not just technical but "mnemotechnical" in the terms of the philosopher Bernard Stiegler, systems of externalised memory (Stiegler 2008).

Both Rheinberger and Stiegler draw inspiration from the writings of Jacques Derrida. He regards the kind of ambivalence expressed by my informants as a general symptom consequent of all processes of working with and through externalisations. This ambivalence is traced to the "very condition of systematicity or seriality in general" (Derrida 2004, 106). As external artefacts, inscriptions can be "generated, displaced, and superposed," material manipulations which facilitate the grasp of their complex inter-relatedness. But in the same movement the author relinquishes control of what is embodied there. Just like Bachelard, therefore, Stiegler offers a normative stance on images as instances of externalisation. Technical systems materialise knowledge and thus render it workable for all sorts of new kinds of "distributed 
cognition" (Hutchins 1995), but they equally always harbour the potentiality to "short-circuit" knowledge (Stiegler 2010, 35), blocking access to certain parts of the network.

In the opinions of my informants, the image poses an obstacle, a) when it convinces through aesthetic compulsion; and b) when it is therefore taken "out of context." The proper context is one in which the intrinsic limitations of the simulation that generated the image are known. What represents and how it represents, we are told by a wave of contemporary philosophers, depends on the context (Suárez 2010; van Fraassen 2008; Giere 2004). But the thing about inscriptions is that they can travel. Images travel beyond the site of their generation, and along the way there is the possibility of sloughing off accompanying contextual markers, with a variety of legitimacy-bolstering or undermining effects (Lahsen 2005). These markers are put down in written form in order that they may entwine the travelling image in a mnemotechnical circuit, enveloping it with traces of its origin. In publication, it is epistemically virtuous to mark the narrative with caveats, largely consequences of the idealisations through which the simulation was made. "Some models," said one informant, "simply can't answer the question you want to ask." But whether or not you can tell if a given model can answer your question depends on what has accompanied it on its travels. Obviously given the Sisyphean nature of attempting to "give" the whole context (where could you possibly draw the line?), the question is one of judging the merits of the fragments that remain.

Science, like many human activities, occurs among technical systems. But any externalisation has its independence, what often seems an animistic "life of its own." It cannot be fully controlled, even by those with the strongest claims to authorship. The problem for images, as expressed by my informants, is a problem of control which relates to the materiality of the systems they create, manipulate, and eventually render partially independent. Images are accompanied by a web of other inscriptions that embody the much less tangible relations between the image and its site of production. It is the relation between the image and these other inscriptions that constitutes the risk of the short-circuit, and the point at which any configuration stands to be judged as good or bad. This relation is too often eclipsed in the second-order accounts of social scientists and philosophers by another relation, its more assertive neighbour, that between the simulation and the reality it simulates, which under the name of validation is the focus for a huge amount of concern and practical labour.

There is no reason to expect that this kind of problem will be confined to computational science. Anxieties about representation in many different spheres have crystallised around images (Maurer 2006). But the novelty of computational methods and the disturbance they pose to established forms of science raises questions about legitimacy with particular force, and images in this field find 
themselves the outlet for much wider concerns for those whose agency and identity are bound up in these pursuits.

The robustness of the travelling image stands in contrast to the fragility of its relations to the traces of its context, the explanations of its origins in a particular time and place, a particular research project, a model with a history and specific limits. Despite all the scientists' best efforts, this contrast cannot be overcome. The textual accompaniment is always at risk of being insufficiently explained or just written badly or wrongly. "You can't write it all down in your paper," says one interviewee, "and even if you do, you might get it wrong. There are examples where someone has written a paper and has got something wrong in their description of what they did, and when you go and look at the original source code, they actually did it right." There is always a risk of being skimmed over, skipped, ignored, misinterpreted, mistranslated, lost, or forgotten. Or maybe the image is just too compelling.

In my attempt to interpret the scientists' complaints, therefore, the key issue becomes not the image as such. Nor is it the context for visual representation. It is the material-cognitive interrelations between visual inscriptions and the markers of their context, as these wind their way through the networks of scientific culture. Such worries about images are more than a local expression of the troubles with representation. For we should not accept the assumption that the natural state of culture is stasis and coherence, but open our eyes to human agency among the exigencies of symbolic decomposition (Wagner 1981). These scientific troubles would then instantiate in a microcosm the feats and frustrations of assembling culture, working against the broadest tendencies of things to fall apart.

\author{
Matt Spencer \\ Centre for Cultural Studies \\ Goldsmiths, University of London \\ United Kingdom \\ mspencer421@googlemail.com
}

\title{
REFERENCES
}

Bachelard, Gaston. 1968. The Philosophy of No: A Philosophy of the New Scientific Mind. Trans. G. C. Waterston. New York: The Orion Press.

Bachelard, Gaston 2002. The Formation of the Scientific Mind. Trans. Mary McAllester Jones. Manchester: Clinamen Press.

Derrida, Jacques. 1974. Of Grammatology. Trans. G. C. Spivak. Baltimore: John Hopkins University Press

Derrida, Jacques. 2004. Dissemination. Trans. Barbara Johnson. London: Continuum. 
Giere, Ronald N. 2004. How models are used to represent reality. Philosophy of Science 71(5): 742-752.

Heidegger, Martin. 1978. Being and Time. Trans. John Macquarrie and Edward Robinson. Oxford: Blackwell.

Hutchins, Edwin. 1995. Cognition in the Wild. Cambridge, MA: MIT Press.

Lahsen, Myanna. 2005. Seductive simulations? Uncertainty distribution around climate models. Social Studies of Science 36(6): 895-922.

Latour, Bruno, and Peter Weibel. 2002. Iconoclash: Beyond the Image Wars in Science, Religion and Art. Cambridge, MA: The MIT Press.

Maurer, Bill. 2006. Does money matter? Abstraction and substitution in alternative financial forms. In Materiality, ed. Daniel Miller, 140-164. Durham: Duke University Press.

Myers, Natasha. 2006. Animating mechanism: Animations and the propagation of affect in the lively arts of protein modelling. Science Studies 19(2): 5-30.

Rheinberger, Hans-Jörg. 1997. Toward a History of Epistemic Things: Synthesizing Proteins in the Test Tube. Stanford: Stanford University Press.

Stiegler, Bernard. 2008. Technics and Time, 2: Disorientation. Trans. Stephen Barker. Stanford: Stanford University Press.

Stiegler, Bernard. 2010. For a New Critique of Political Economy. Cambridge: Polity Press. Suárez, Mauricio. 2010. Scientific representation. Philosophy Compass 5(1): 91-101.

Turkle, Sherry. 2009. Simulation and Its Discontents. Cambridge, MA: MIT Press.

van Fraassen, Bas. 2008. Scientific Representation: Paradoxes of Perspective. Oxford: Clarendon Press.

Wagner, Roy. 1981. The Invention of Culture. Revised and expanded ed. Chicago: University of Chicago Press. 